Please do not remove this page

RMIT

UNIVERSITY

\title{
Terrestrial methods for monitoring cliff erosion in an urban environment
}

Gulyaev, S.A.; Buckeridge, John

https://researchrepository.rmit.edu.au/esploro/outputs/9921860164901341/filesAndLinks?institution=61RMIT_INST\&index=null

Gulyaev, S. A., \& Buckeridge, J. (2004). Terrestrial methods for monitoring cliff erosion in an urban environment. Journal of Coastal Research, 20(3), 871-878.

https://researchrepository.rmit.edu.au/discovery/fulldisplay/alma9921860164901341/61RMIT_INST:Resea rchRepository

Repository homepage: https://researchrepository.rmit.edu.au

(C) 2004 The Coastal Education and Research Foundation

Downloaded On 2023/04/26 13:05:16 +1000

Please do not remove this page 


\title{
Terrestrial Methods for Monitoring Cliff Erosion in an Urban Environment
}

\author{
S.A. Gulyaev and J.S. Buckeridge \\ Earth and Oceanic Science Research Institute \\ Auckland University of Technology \\ Private Bag 92006 \\ Auckland 1020, New Zealand \\ sergei.gulyaev@aut.ac.nz
}

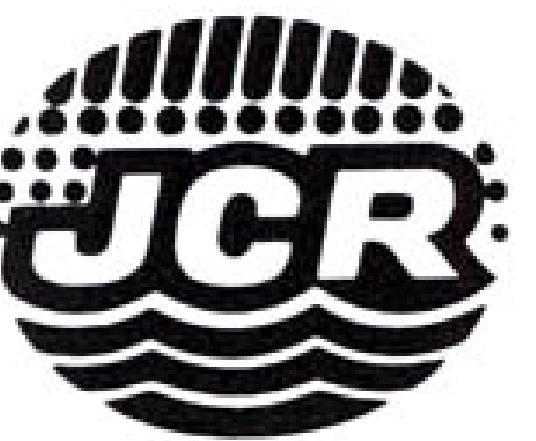

\begin{abstract}
GULYAEV, S.A. and BUCKERIDGE, J.S., 2004. Terrestrial methods for monitoring cliff erosion in an urban environment. Journal of Coastal Research, 20(3), 871-878. West Palm Beach (Florida), ISSN 0749-0208.

Terrestrial methods that may be used to quantify cliff erosion rates, and to qualify the real status of coastal areas currently zoned for building are described. The methods are fast, inexpensive and effective for relatively small terrains. Due to the use of modern methods and instruments, a very high (sub-centimetre) accuracy for measuring cliff recession can be reached. A computer model is derived to analyse data obtained through the measurement techniques. The model will, over time, supply data sufficient to project short to medium term volumetric changes in rock mass and will provide significant input in the development of a coastal hazards zoning protocol. A pilot study has been carried out in North Shore City (Auckland, New Zealand).
\end{abstract}

ADDITIONAL INDEX WORDS: Urban seashore, short-term monitoring, laser scanning, terrestrial photogrammetry, digital terrain model.

\section{INTRODUCTION}

The presence of "vegetation free" cliffs along any seashore is generally an indication of active erosion. In an urban environment, such cliffs provide excellent sea views for those who build upon them. They may also provide a healthy land tax income for local authorities. There is thus potential for conflict-between parties who wish to sub-divide land close to the sea, parties who wish to live there, parties who wish to increase land tax revenue and parties who are concerned about the sustainability of "cliff-top dwellings".

From a global perspective, the urbanisation of New Zealand has been a relatively recent phenomenon. None-the-less, it has not necessarily been achieved with the level of planning that one might expect "in hindsight". Population growth has been most rapid in the Auckland metropolitan area, where cities like North Shore City have suffered the malaise stochastic urban accretion (SUA) - in allusion to the failure of services such as sewage and storm-water reticulation (BUCKERIDGE, 1999).

Like most of New Zealand's larger cities North Shore City is not far from the sea. Over the past few decades, lateral growth has been limited by regional boundaries, with the result that a high proportion of new housing is either infill housing or is on sites previously considered unstable. In the area of this study, poorly maintained sewage and storm-water systems, and weakly enforced earthworks activities have respectively resulted in raw sewage release and unacceptably high silt loads in streams, which in turn have smothered shallow water marine organisms. Some of the most recent

02063 received 10 May 2002; accepted in revision 20 July 2003. housing developments have been close to sea cliffs, and the lack of vegetation on these cliffs is testament to active erosion. The council's imperative to allow housing so close to eroding cliffs is surprising, as there are numerous examples of active subsidence in the area (KERMODE, 1992; BUCKERIDGE, 1995; EDBROOKE, 2001). Apart from obvious human calamities, any subsidence actively contributes to the silt load of an already overstressed marine ecosystem.

Existing methods for measuring cliff erosion rates can be classified into 4 categories (see Table 1). They are: (a) oblique and vertical aerial photography (DoLAN et al., 1991; JoNES et al., 1993; WrAY et al., 1995); (b) airborne laser scanning (Corbley, 2001; PAlm and Lohr, 2001; TurbotT, 2001); (c) cartographic measurements using sequential historical maps (Rosengran, 1985; Gray, 1988; Brodnax, 1991); (d) direct field measurements such as repetitive surveys, beach profiling techniques, cliff top pegs, etc. (EMERY, 1961; BIRD, 1985; Smith and Zarillo, 1990; Jones and Williams, 1991).

Because of difficulties with specifying the exact edge of the cliff from an aerial perspective (e.g. masking by overhanging trees and the cliff geometrical profile: Figure 1, a-b) and inherent errors, the accuracy of aerial photography methods is typically 1-5 m. Modern airborne laser scanning technique provides higher horizontal accuracy-from $20 \mathrm{~cm}$ (CORBLEY, 2001) to $1 \mathrm{~m}$ (PALM and LoHR, 2001; Brock et al., 2002)but it is also not free from vegetation and other "edge" problems. Erosion rates at Long Bay (near Auckland, New Zealand) were found to vary from $5 \mathrm{~cm} /$ year to $50 \mathrm{~cm} /$ year, which is common for Waitemata Harbour area (BRODNAX, 1991). Comparing typical erosion rates (about $10 \mathrm{~cm} /$ year) with accuracy of the standard methods (about $1 \mathrm{~m}$ ), it can be dem- 
Table 1. Methods for clifferosion study and their accuracy. (See references in the text.)

\begin{tabular}{lc}
\hline \hline \multicolumn{1}{c}{ Method } & Accuracy $(\mathrm{m})$ \\
\hline Aerial photography & $1-5$ \\
Airborne laser scanning & $0.2-1$ \\
Cartography-sequential historical maps & $3-5$ \\
Direct field measurements & $0.2-1$ \\
\hline
\end{tabular}

onstrated that relatively large intervals of time are needed (some 20-50 years) to estimate the erosion rate with sufficient level of confidence $(>65 \%)$.

The existing airborne methods are both "slow" and costly (requiring expensive aerial/airborne scanning techniques); they fail when considering undercut (negative slopes) cliffs (Figure 1, c). Therefore, to quantify cliff erosion rates in urban coastal areas currently zoned for building, modern "terrestrial methods" may be used, such as (a) terrestrial laser scanning, and (b) terrestrial photogrammetry methods.

In this paper we develop these methods and demonstrate that they have advantages over aerial techniques, particularly pertaining to small areas that need to be analysed quickly and cost effectively. The high accuracy of these methods (sub-cm for the laser scanning technique and sub-dm for terrestrial photogrammetry) allows estimating the cliff recession rate over a period as brief as $2-5$ years (compared with 20-50 years of other methods). The only ongoing cost of such an operation is labour (e.g. a cliff face approximately $40 \mathrm{~m}$ long and $25 \mathrm{~m}$ high can be mapped in a morning). We present the results of the pilot study and show that the methods are safe, easy-to-use and accurate with good repeatability.

\section{TERRESTRIAL METHODS AND MATHEMATICAL ALGORITHM}

Accurate terrestrial methods are based on repetitive surveying (through time) of a cliff face from a station situated on the shore. The objective of a survey is to create sequential digital models of the cliff face, with a resultant vertical digital terrain model (VDTM). A VDTM is analogous to digital elevation model (DEM), however, in a VDTM, a vertical rather than horizontal plane is used as the reference plane. The vertical reference plane (VRP) may pass through the base station and may be parallel to the shore boundary of the cliff (Figure 2). Horizontal distances from points on the cliff face to the VRP play the same role in VDTM as elevation plays in DEM.

In this section we develop two terrestrial methods for cliff erosion rate measurements: (a) terrestrial laser scanning, and (b) terrestrial photogrammetry. Both methods are not 'site specific', and can be applied to any cliff-face study site. They do not rely wholly on special benchmarks at the base of the cliff, or in the face of the cliff for maintaining accuracy, as these may be lost through rockfall and erosion. In both methods the base station has been co-ordinated to sub-cm accuracy with two Leica GS-50 GPS in the static mode.

The terrestrial photogrammetry (TPG) method is based on processing two images (stereo pairs) and creation of a VDTM of the cliff face. The images are taken from the fixed station

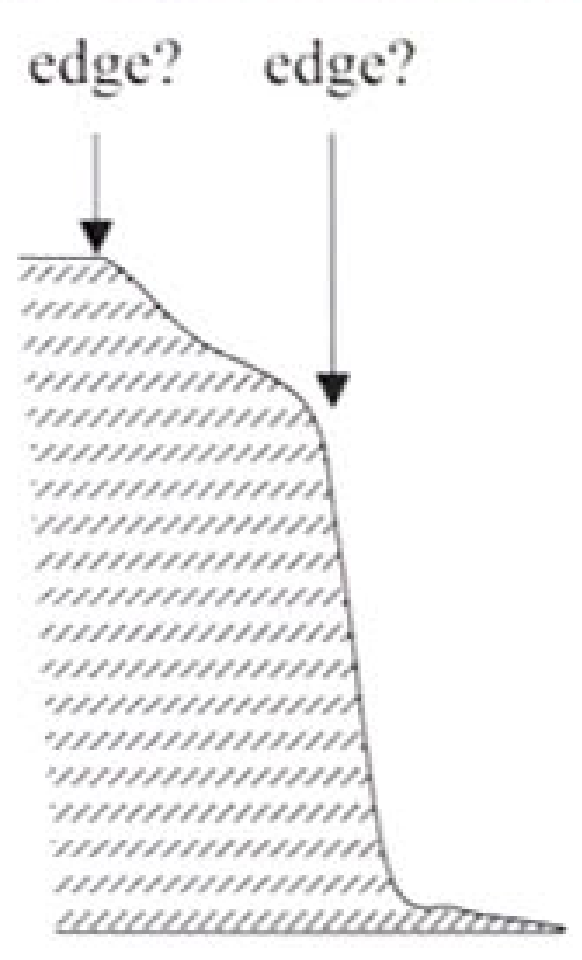

(a)

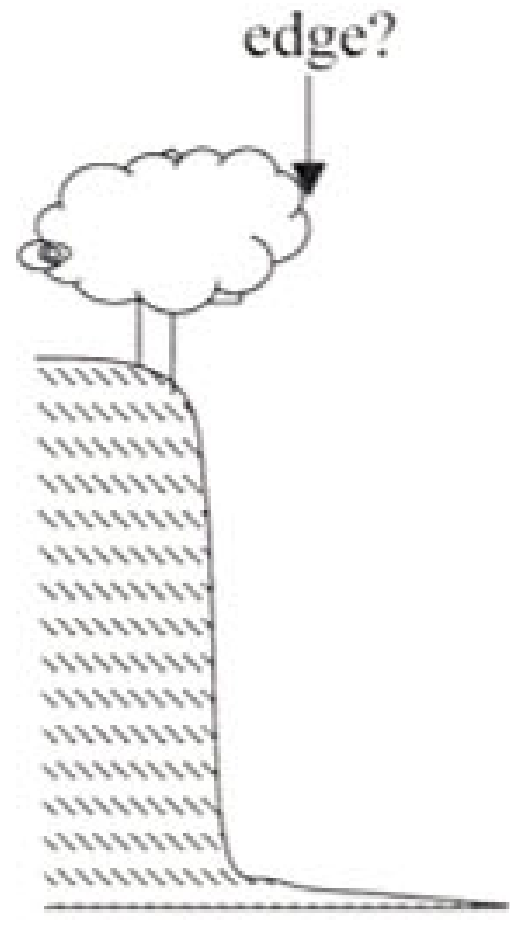

(b)

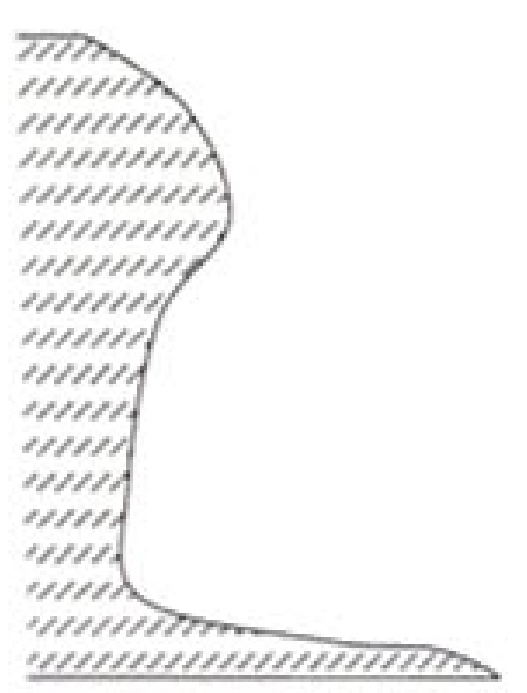

(c)
Figure 1. Cliff profiles, which reduce accuracy of the aerial measurement methods: (a) geometrical profile of the cliff makes position of the cliff edge uncertain; (b) overhanging trees make it difficult to find the cliff edge; (c) cliff with an undercut.

on the shore at the cliff base (Figures 2 and 3), with the help of the identical digital cameras mounted on either ends of a horizontal bar. In order to create the VDTM, the images are orthorectified. The block-matching algorithm and normalized cross-correlation procedure are used to match the images and to calculate the $x$-axis offsets (parallaxes), which are inversely proportional to distances from the station to the points on the cliff. Both automated and interactive procedures have been programmed with the MatLab Image Processing Toolbox.

Consider the stereo-pairs, which have been taken from successive camera stations $S_{1}$ and $S_{2}$, having principal points $c_{1}$ and $c_{2}$ (Figure 4). A random point $A$, on the cliff face, is represented by the points $a_{1}$ and $a_{2}$ on the photographs. Through $S_{2}$ draw $S_{2} a^{\prime}{ }_{1}$ which is parallel to $S_{1} a_{1}$. Then $c_{1} a_{1}=c_{2} a^{\prime}{ }_{1}$. Hence $a_{2} a^{\prime}{ }_{1}$ is the absolute parallax of $A=P_{a}$.

Since triangles $S_{1} S_{2} A$ and $S_{2} a_{2} a^{\prime}{ }_{1}$ are similar,

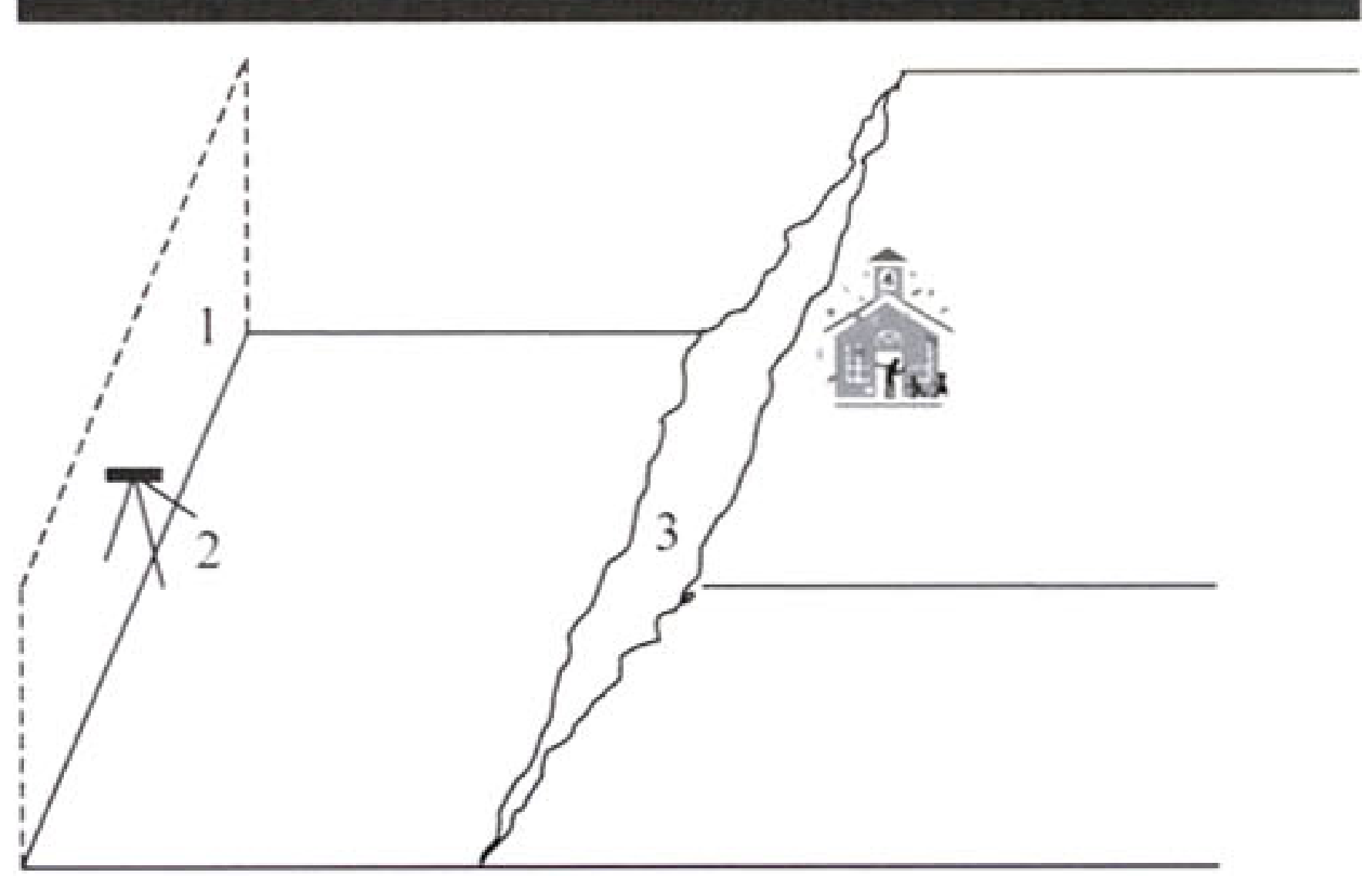

Figure 2. Set up: the vertical reference plane (1), which is parallel to the coastal line and passes through the instrument (2). Cliff face (3) is shown schematically. 


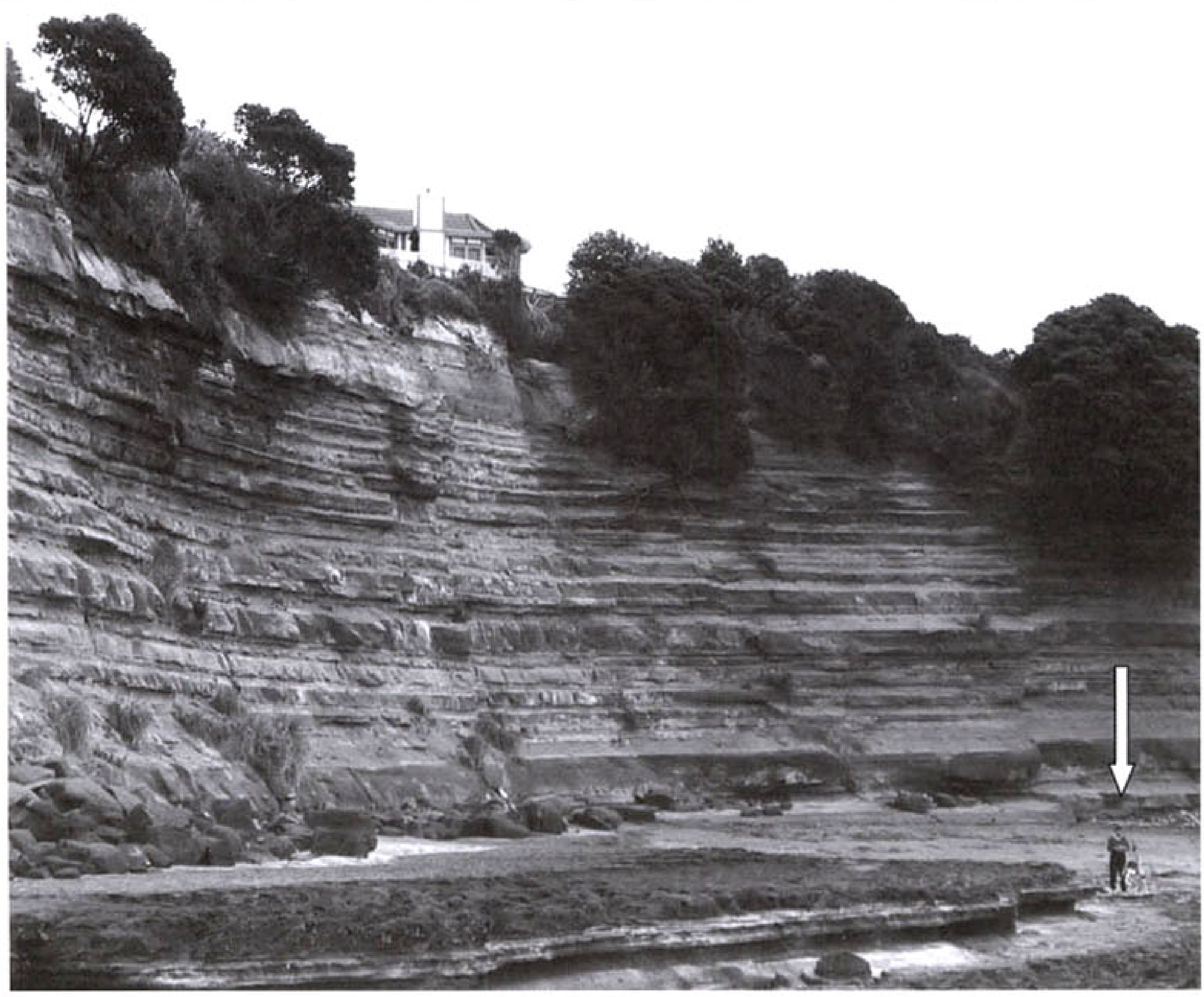

Figure 3. Cliff face at Gilbert Place Cove (from Gulyaev and Buckeridge, 2001). The central portion below the house shows evidence of recent, minor slumping. This erosion occurred before the project was initiated. Figure standing on base station (arrow).

$$
\frac{A_{2} a_{1}^{\prime}}{S_{2} c_{2}}=\frac{S_{1} S_{2}}{A M}
$$

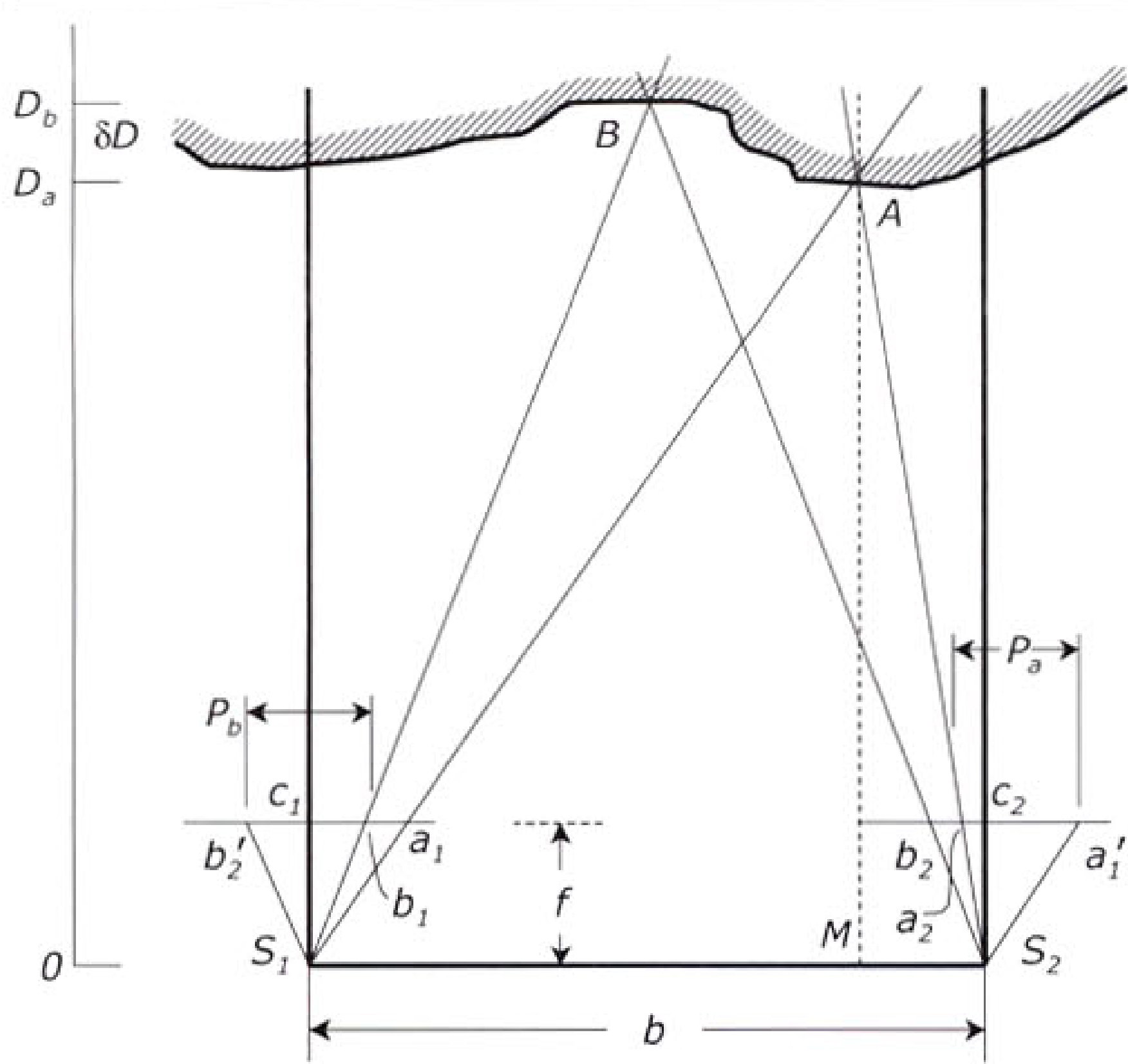

Figure 4. On the problem of accuracy of the terrestrial photogrammetry method: the geometry of parallax in a pair of photographs.
Or, substituting the usual values in the expression:

$$
\frac{P_{a}}{f}=\frac{b}{D_{a}}
$$

therefore

$$
P_{a}=\frac{b f}{D_{a}}
$$

where $f$ is the camera focal length, and $b$ is the base (Figure 4).

If a second random point $B$ is selected, the absolute parallax of this point will be:

$$
P_{b}=\frac{b f}{D_{b}}
$$

Thus the parallax difference between the images of $A$ and $B$ may be expressed as:

$$
P_{a}-P_{b}=b f\left(\frac{1}{D_{a}}-\frac{1}{D_{b}}\right)
$$

Now substituting 


$$
\begin{aligned}
P_{a}-P_{b} & =\delta P_{a b} \text { and } \\
D_{b}-D_{a} & =\delta D
\end{aligned}
$$

we get

$$
\delta D=D_{a} D_{b} \frac{\delta P_{a b}}{b f}
$$

Taking into account (3), we finally get the principal equation:

$$
\delta D=D_{a} \frac{\delta P_{a b}}{P_{b}}
$$

Thus if the horizontal distance of one point on the cliff face, $D_{a}$, and the base, $b$, between the two camera stations are known, it is possible to evaluate the absolute parallax of the point. If the difference in parallax is measured between this point and any other within the same overlap, the difference in horizontal distances between the two points may be evaluated from equation (6).

The camera resolution is a factor that limits the accuracy of the method. To estimate the horizontal distance error in the terrestrial photogrammetry method, one can rewrite equation (5) for the situation when $\delta P_{a b}=\delta P$ corresponds to the size of one pixel on the camera CCD. The horizontal distance error is then

$$
\delta D=D^{2} \frac{\delta P}{b f}
$$

where $D_{a} \approx D_{b}=D$. For a digital camera, equation (7) can be transformed to the readily usable formula:

$$
\delta D \approx \frac{D^{2}}{2 b \sqrt{N}}
$$

where $N$ is the resolution (in pixels) of the camera.

In our pilot study at Long Bay, $D \approx 25 \mathrm{~m}$, and $b=2 \mathrm{~m}$. The accuracy in measuring distances from the base station to the cliff points was therefore restricted by $\delta D \approx 10 \mathrm{~cm}$ limit as we used Canon 2.1-megapixel digital cameras $(N=$ $2.1 \times 10^{6}$ pixels). For higher accuracy high-resolution cameras should be used.

The laser scanning (LS) method (GULYAEV and BuckERIDGE, 2001) involves a scanning procedure, such as pointby-point, layer-by-layer measurements. When the cliff is distinctly stratified, either soft or hard strata layers should be chosen (Figure 3; see also Figure 8, a). In our pilot study at Long Bay we used a Leica TCR300 Total Station incorporating a laser electronic distance meter (EDM), which provided an accuracy for distance measurements of up to $\pm 2 \mathrm{~mm}$ (LEICA, 2000). Altogether 50-100 points are sufficient for a cliff face approximately $25 \mathrm{~m}$ high and $40 \mathrm{~m}$ long. The erosion rate is determined on the basis of repetitive surveys. When resurveying, the base station must then be set up at the same position, orientation and instrument height; and the same points (points with the same bearings) are remeasured. Surveying the cliff from its base excludes the problem of the cliff edge and vegetation, and allows working with undercut cliffs (Figure 1).

Provided laser measurements are performed with high ac- curacy, the main source of inaccuracies is in the data processing method. The mathematical procedure (e.g. creation of the mathematical model of the cliff face, volumetric calculations, etc.) is thus crucial for the high-precision laser scanning method. It was found that the following procedure does not reduce the accuracy of the laser measurements significantly. To transform and analyse data obtained through laser measurement techniques, an ad hoc computer program "CLIFF" was developed that interpolates 3D irregular point data and creates a regular grid, from which a contour map and the VDTM of the cliff face may be created. Figure 5 shows an example of the pseudo-surface of the measured section of the cliff (left), and its transformation to the form of an "elevation" model by rotation 90 degrees (right). Our computer program calculates the volume $V=\iint z(x, y) d x d y$ of the prism between the cliff face and the vertical plane at the origin, as well as the area of the projection of the cliff face to this vertical plane $S=\iint d x d y$.

The procedure of interpolation between irregular point data and creation of the regular lattice of values (grid) is the main source of error limiting accuracy of calculations (see e.g. Wise, 1998; KIDNER et al., 1999). The problem is that both the surface area $S=\iint d x d y$ and the volume $V=\iint z(x, y)$ $d x d y$, calculated on the base of the regular grid, vary dramatically as the grid step $(s)$ changes. Figure 6 (left) shows relative deviation of the calculated volume $V$ from its mean value $\bar{V}$ as a function of the grid step $s$. We found that the ratio $D=V / S=\left[\iint z(x, y) d x d y\right] / \iint d x d y$, however, remains stable when the grid step $s$ changes. Geometrically, $D$ is the length of a prism with the area of the base $S=\iint d x d y$ and volume $V=\iint z(x, y) d x d y . D$ is an integrated characteristic, which is referred to as an equivalent distance between the base station and the cliff face. Figure 6 (right) shows the relative deviation for $D$. The results of our pilot study in Long Bay demonstrate that the error does not exceed $0.02 \%$ when the grid step $s \leq 0.4 \mathrm{~m}$. For the average distance from the base to the cliff of about $25 \mathrm{~m}$, this corresponds to the absolute accuracy of the mathematical procedure of $0.5 \mathrm{~cm}$ for the equivalent distance $D$.

\section{PILOT STUDY AND DISCUSSION}

A pilot study has been carried out at Gilbert Place Cove, Long Bay, on Auckland's North Shore (Figure 7).

Actively eroding, sub-vertical coastal cliffs are common on the eastern seaboard of the North Shore, and reach heights of about 40 metres. Long Bay is characterised by deeply eroded hills rising to about 100 metres above sea level. The principal lithology in the region is Miocene flysch deposited as underwater debris flows, and comprised of interbedded sandstones, siltstones and mudstones. The coarser horizons, lower in the sequence at Long Bay are distinctly tuffaceous, and weather to produce ferruginous Liesegang features. Weathering although variable, may be quite deep, with the regolith extending down to over 5 metres at sites near the Long Bay cliffs. A typical weathering profile that is directly associated with slumping in the area is provided in BUCKERIDGE (1995). On the whole, strata exposed at Long Bay have only been weakly deformed; beds are sub-horizontal, with occasional 


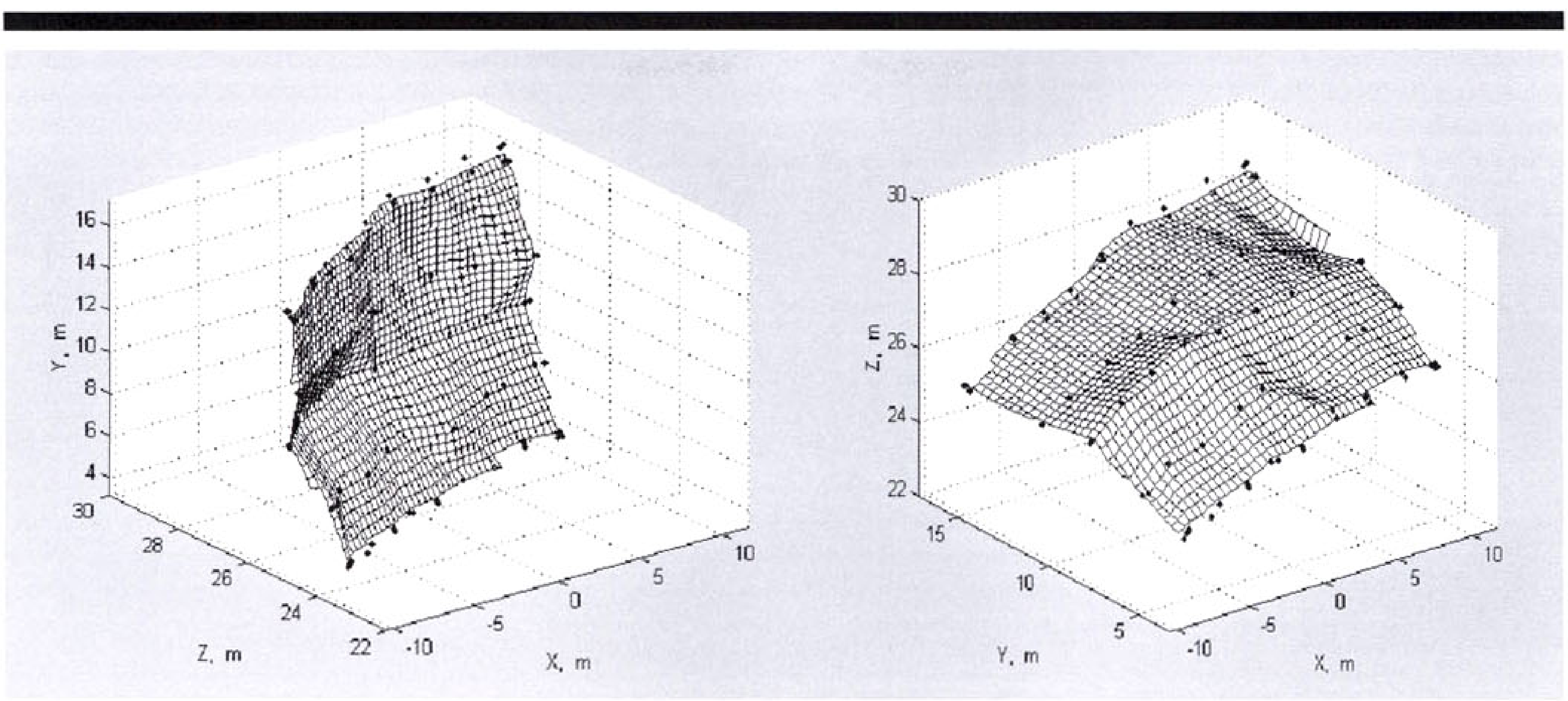

Figure 5. (Left) Pseudo-surface of the measured section of the cliff. (Right) Same, transformed to an "elevation model" view by rotating 90 degrees.

tensional faults (now apparently inactive). In the coastal cliff environment, weathering and mass movement problems are greatest when strata dip gently toward the sea, precipitating dip-slip failure. This structural relationship occurs at Long Bay.

The cliff face was scanned manually with the Leica 7 " Total Station (TC307) along the direction corresponding to the hard strata layers (sandstone) of the cliff. In Figure 8(a) the scanned layers are labelled with letters from $\mathrm{A}$ to $\mathrm{E}$. The accuracy of the laser distance meter (EDM) used is $\pm 2 \mathrm{~mm}$. From the measurements, the Cartesian coordinates $(x, y, z)$ of the points on the cliff face are obtained (Figure 8, b). The origin of the coordinate system was chosen at the position of the instrument (the base station) some 25-30 metres from the cliff. A permanent stainless-steel mark was bonded in a drill hole at this position. Zero horizontal angle direction (" $\mathrm{Hz}=0$ ") was chosen to be more or less perpendicular to the cliff face, and hold-fixed with the help of three witness marks. If one of the marks is lost, it can be restored by surveying from the remaining marks.

The cliff surface at Gilbert Place cove was scanned repeatedly on eight visits over two years. A summary of the calculations is provided in Table 2 . The calculated volume (column 2 ) varies significantly due to the inherent error of the measurement method and the error of the mathematical procedure used (see Figure 6, left, and the discussion in the previous section).

The calculated equivalent distance $(D)$ is given in column 3 of Table 2. The error in equivalent distance is the sum of

- the error of the EDM used $( \pm 0.2 \mathrm{~cm}$, with a $95 \%$ level of confidence),

- the error of positioning the base station $( \pm 0.4 \mathrm{~cm})$, and

- the error of the mathematical procedure (gridding) used $( \pm 0.1 \mathrm{~cm})$.
The resulting error for the equivalent distance is therefore $\pm 0.7 \mathrm{~cm}$ with a $95 \%(2 \sigma)$ level of confidence. Corresponding error bars are shown in Figure 9.

Figure 9 shows the dynamics of the equivalent distance $D(t)$. The difference $d D=D(t)-D_{0}$, where $D_{0}=2676.5 \mathrm{~cm}$, is plotted as a function of time. A linear regression analysis was performed for all two-year period of monitoring (solid line in Figure 9), as well as for one-year time intervals (dashed lines). The trend line equations, regression coefficients, $R^{2}$, and the rates of erosion, $d D / d t$, are indicated in Figure 9 .

During the first year of observations, the equivalent distance remained almost constant: the calculated rate of recession in this instance was $d D / d t=1.0 \pm 0.9 \mathrm{~cm} /$ year. In the second year, the rate of recession was found to be $d D / d t=$ $3.3 \pm 1.2 \mathrm{~cm} /$ year. The whole two-year period is characterised by the rate of recession $d D / d t=2.4 \pm 0.7 \mathrm{~cm} /$ year (the solid line in Figure 9). All the results are presented with a $95 \%$ $(2 \sigma)$ level of confidence.

The rate of cliff erosion $d D / d t=2.4 \pm 0.7 \mathrm{~cm} /$ year found over a two-year monitoring of the cliff section at Gilbert Place Cove, Long Bay is relatively low compared to previous studies in this area. Cartographic measurements using sequential historical maps were undertaken at Long Bay area by BRODNAX (1991). He estimates erosion rates at Long Bay from 5 to $50 \mathrm{~cm} /$ year, with the rate of erosion at Gilbert Place Cove of 10-15 cm/year. Our low erosion rate result confirms significant irregularity in erosion rates for the coastline in an urban area (see e.g. BuckERIDGE, 1995).

\section{CONCLUSION}

Two terrestrial methods for study cliff erosion are presented. They permit working with "difficult" objects (from the aerial photography point of view), such as cliffs with overhang- 

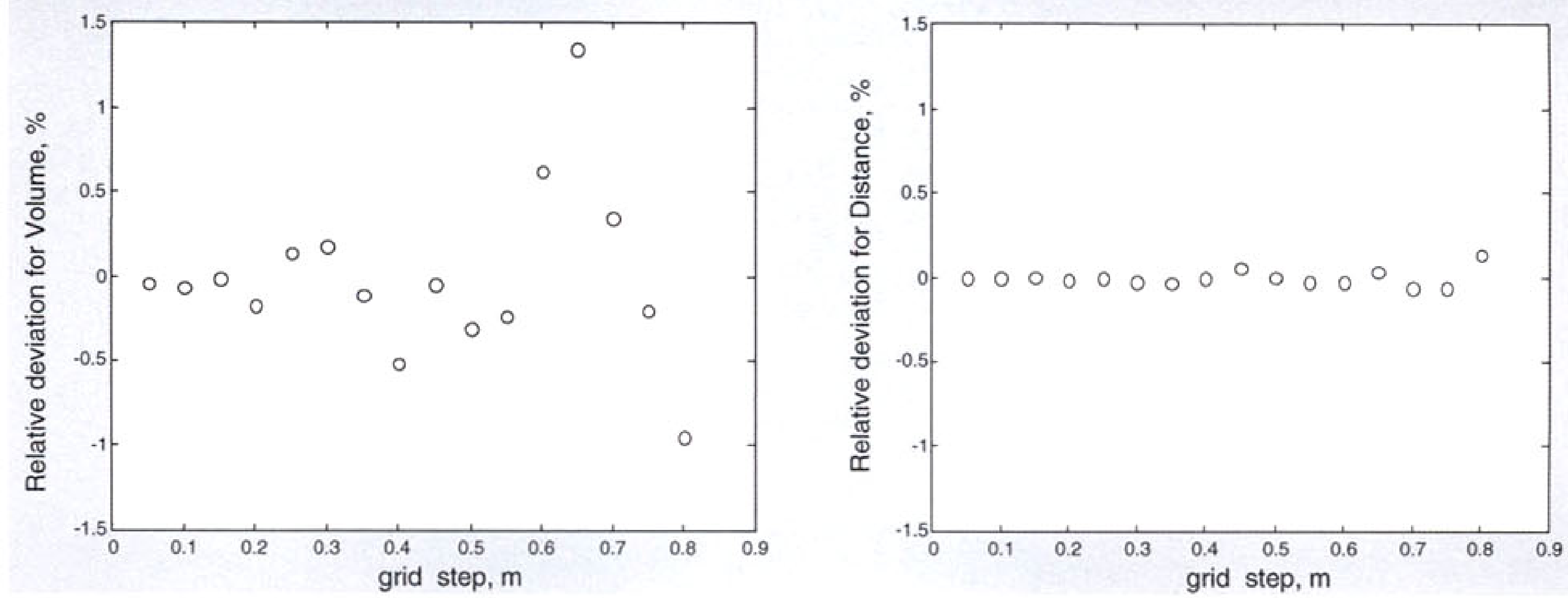

Figure 6. Relative deviation (\%) for volume $V$ (left), and for the equivalent distance $D$ (right).

ing vegetation or undercut cliffs. Both methods are based on surveillance of the cliff face from a point on the shore between the cliff and the sea, and creation of a 3-D model of the cliff (VDTR-vertical digital terrain model). In this study, a mathematical approach based upon the notion of the equivalent distance is used to assess the cliff recession rate. Equivalent distance is especially valuable for monitoring problems. It remains stable when applying different types of model (e.g. grid, TIN), and is not sensitive to the details of the particular method (e.g. size of the grid step).

The terrestrial photogrammetry method is fast, easy-to-use and inexpensive. The method is more accurate than the aerial photography method. In the pilot study we reached $10-\mathrm{cm}$ level of accuracy for the horizontal distance from the vertical reference plane to a point on the cliff face. Due to relatively poor accuracy of this method $( \pm 10 \mathrm{~cm})$, any changes in the cliff face due to erosion were not able to be determined during the two-year period of monitoring.

The laser scanning method preserves all the advantages of the terrestrial photogrammetry method. However, the former is much more accurate. It permits measuring the linear characteristic of cliff erosion with sub-centimetre accuracy. This means that even seasonal changes can be monitored for sites with typical recession rates of $10-20 \mathrm{~cm} /$ year. The method

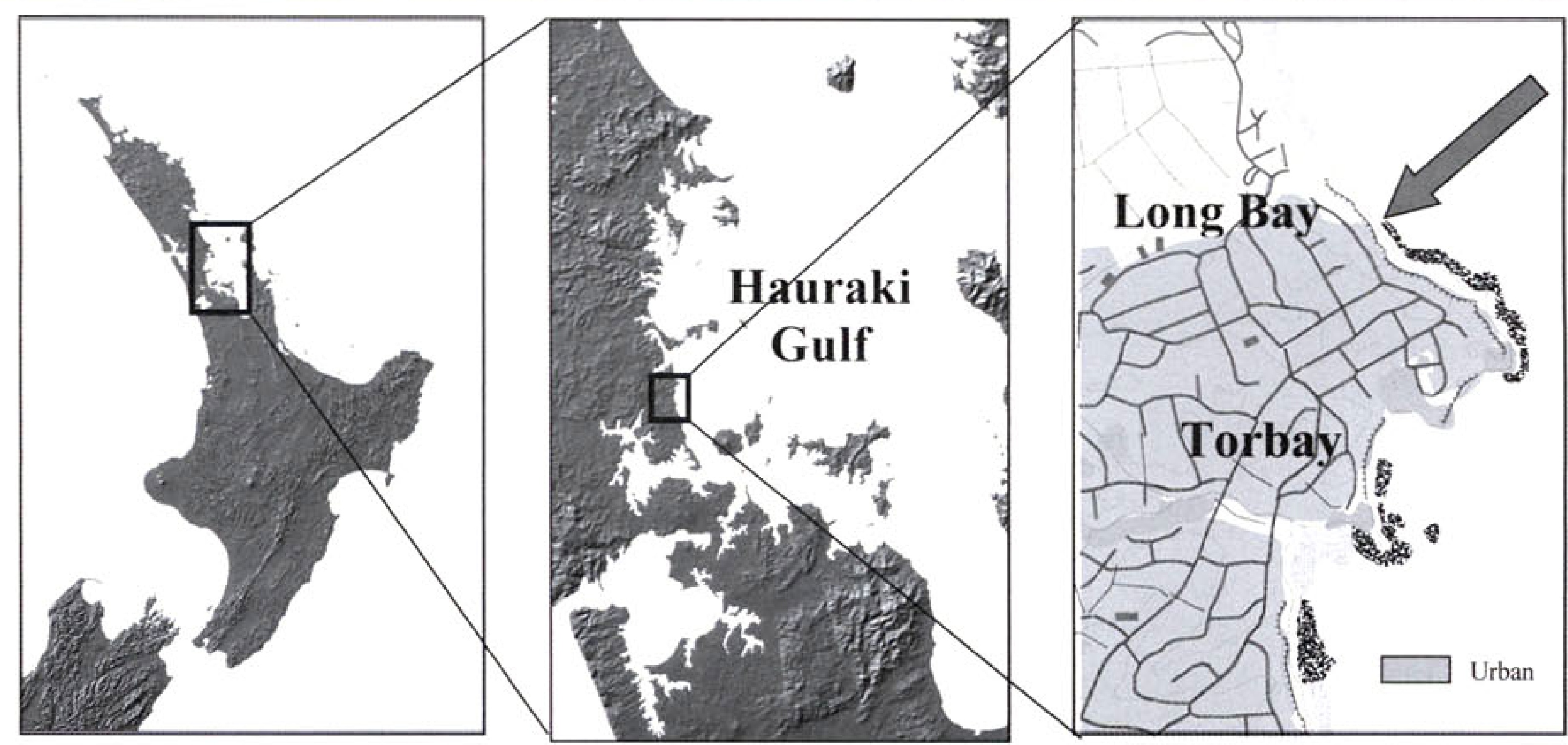

Figure 7. Site locality: (A) New Zealand North Island; (B) Hauraki Gulf and Auckland region; (C) Urban area in North Shore City. Arrow points at Gilbert Place Cove. 


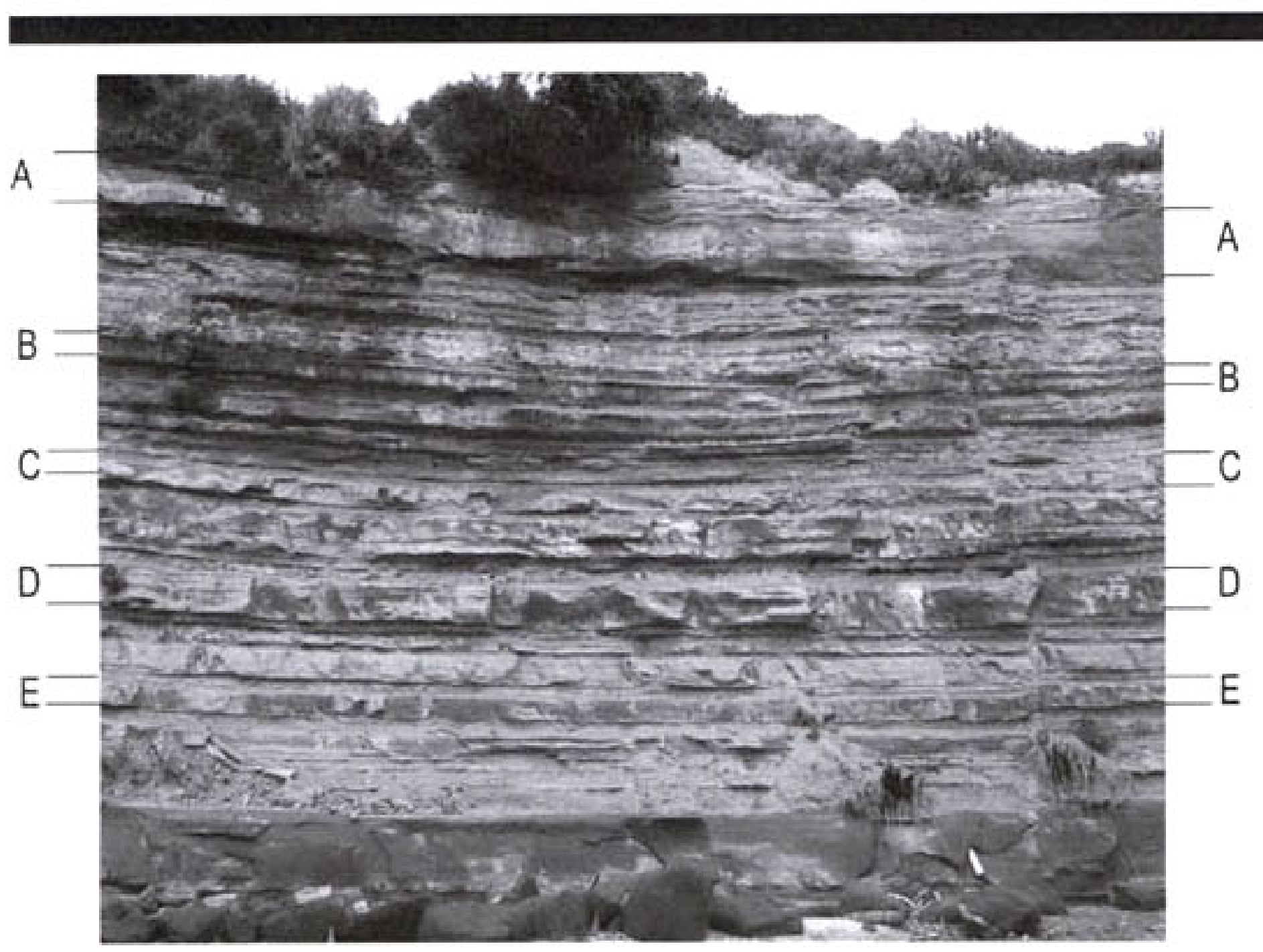

(a)

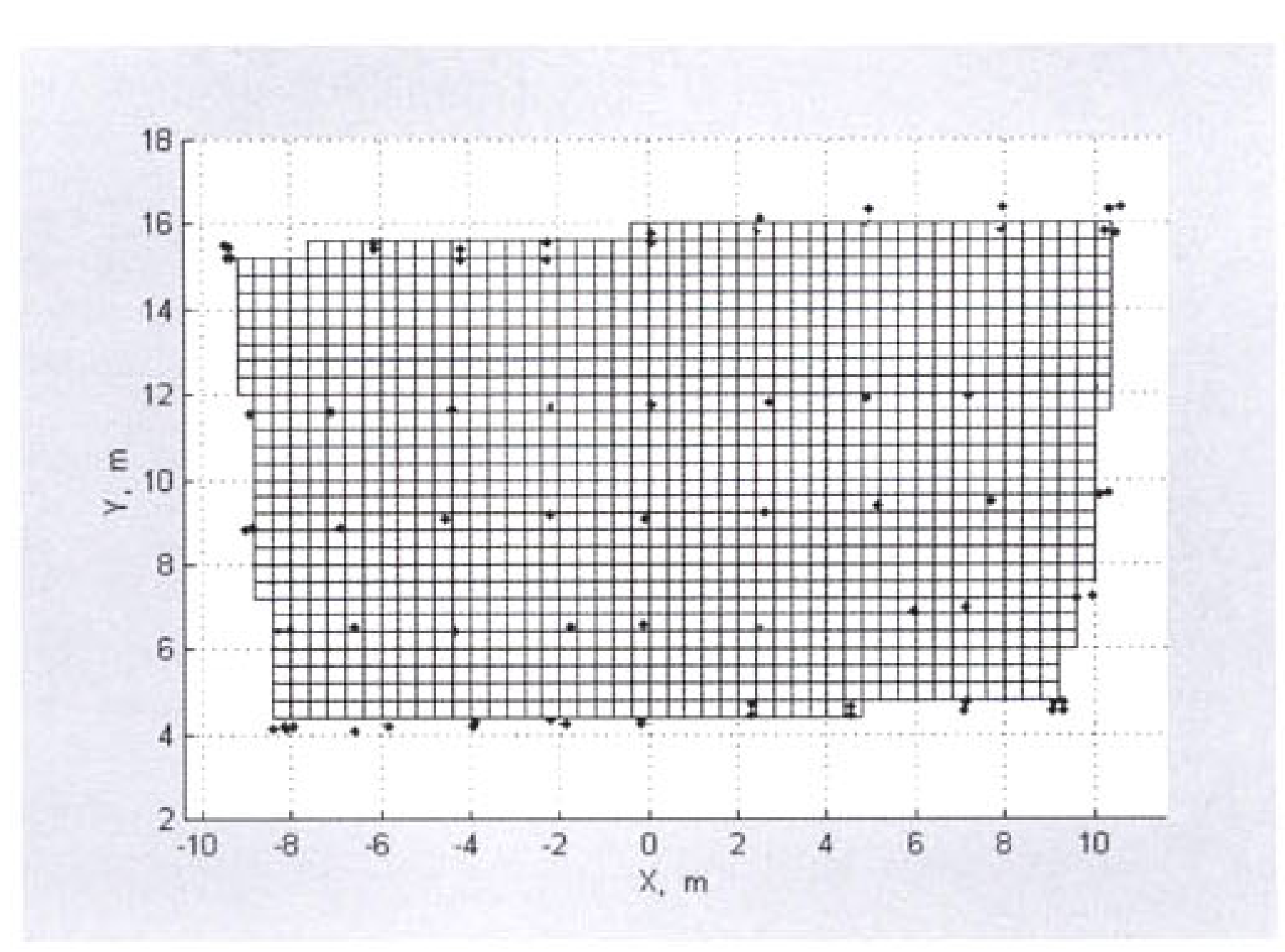

(b)

Figure 8. (a) Cliff face with the labelled layers (before orthorectification). (b) Projection of the calculated grid onto the vertical ( $x, y$ ) plane normal to " $\mathrm{Hz}=0$ " direction. The measured points are shown with dots. $x$ and $y$ in metres.

may be used irrespective of overhanging vegetation and cliff edge problems, providing bare rock is exposed. This method is effective for relatively small terrains, some 30-40 metres in length - the size of a land parcel. It can be used for evaluation of the cliff erosion rate for a private property or historical building at the top of the cliff, as well as for a potentially dangerous section of a road at the bottom (or top) of a cliff. After the station is coordinated, measurement of the set of 70 points on the cliff face takes 2 hours for a trained technician; the equipment used is standard surveying equipment. The method is safe providing the shore platform is well exposed at low tide (the base station is situated $20-30$ metres from the foot of the cliff).

Due to their high accuracy and low cost, terrestrial methods are superior to aerial methods when assessing small terrains in urban environment and will, over time, supply data sufficient to project short to medium term volumetric changes in rock mass, as well as providing significant input in the development of a zoning protocol for coastal hazards.

Table 2. Results of the pilot study at Long Bay, Auckland: volume, V, and equivalent distance, $D$, as calculated using program "CLIFF".

\begin{tabular}{ccc}
\hline \hline Date & $\begin{array}{c}\text { Volume } \\
\left(\mathrm{m}^{3}\right)\end{array}$ & $\begin{array}{c}\text { Equivalent } \\
\text { Distance }(\mathrm{m})\end{array}$ \\
\hline 5 June, 2001 & 6056.6 & 26.769 \\
22 June, 2001 & 6056.5 & 26.766 \\
20 September, 2001 & 6059.8 & 26.771 \\
3 October, 2001 & 6058.6 & 26.770 \\
20 March, 2002 & 6060.0 & 26.775 \\
9 October, 2002 & 6066.2 & 26.794 \\
4 April, 2003 & 6051.0 & 26.806 \\
18 June, 2003 & 6072.8 & 26.818 \\
\hline
\end{tabular}

\section{ACKNOWLEDGMENTS}

We thank Subana Shanmuganathan (graduate student, EOS) for help with image processing and Granville Poundall (School of Engineering, AUT) for constructing the equipment used in stereo photography.

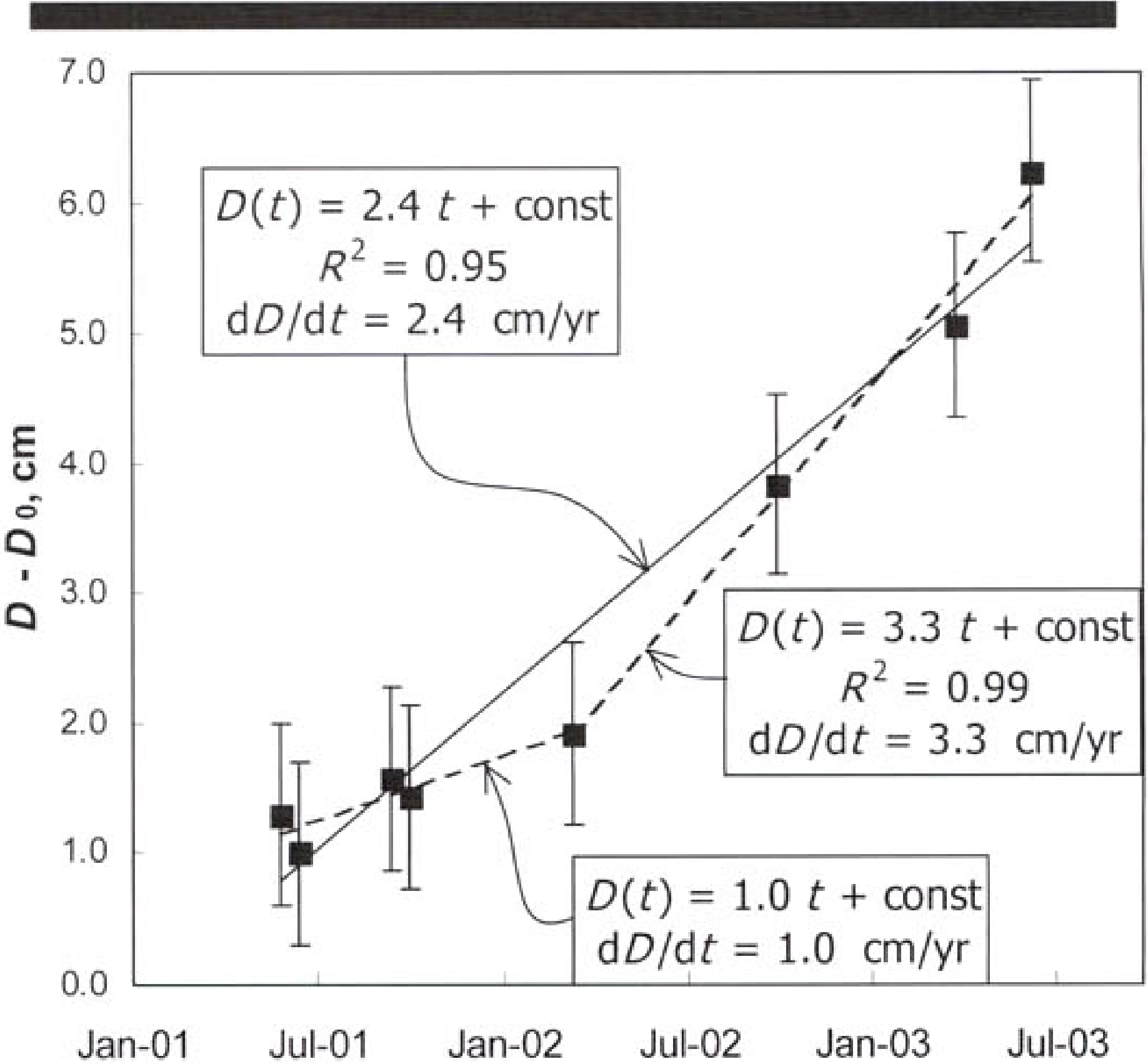

Figure 9. Shows the calculated equivalent distance change, $\Delta D=D(t)$ $-D_{0}$, as a function of time. Linear regression analysis results are shown with solid and dashed lines. The trendline equations, regression coefficients, $R^{2}$, and the rates of erosion, $d D / d t$, are indicated. 


\section{LITERATURE CITED}

BIRD, E.C.F., 1985. The study of coastal line changes. Zeitschrift für Geomorphologie, Supplementband 57, 1-9.

Brock, J.C.; Wright, C.W.; Asbury, H.S.; Krabill, W.B., and SwIFT, R.N., 2002. Basis and Methods of NASA Airborne Topographic Mapper Lidar Surveys for Coastal Studies. Journal of Coastal Research, 18, 1-13.

Brodnax, R.C., 1991. Cliff erosion in the Waitemata Harbour and Hauraki Gulf. M.Sc. Thesis, University of Auckland, $145 \mathrm{p}$.

BuCKERIDGE, J.S., 1995. Land stability in Urban Sites of the North Shore, Auckland, NZ. In: Bell, D.H. (ed.). Proceedings of the Sixth International Symposium on Landslides (Balkema, Rotterdam), 3, pp. 2129-2136.

BuCKERIDGE, J.S., 1999. Stochastic Urban Accretion and Marine Reserves: Complementary or Conflicting options? Proceedings of the 19th Annual Meeting of the International Association for Impact Assessment: Impact Assessment for a New Century (Glasgow, UK), $10 \mathrm{p}$.

CORBLEy, K.P., 2001. Coastal attrition modelling erosion in 3D. Geospatial Solutions, 11, 36-39.

Dolan, R.; Fenster, M.S., and Holme, S.J., 1991. Temporal analysis of shoreline recession and accretion. Journal of Coastal Research, 8, 641-654.

EDBROOKE, S.W., 2001. Geology of the Auckland area. Scale 1:250 000. Institute of Geological and Nuclear Sciences geological map 3. Lower Hutt, New Zealand. Institute of Geological \& Nuclear Sciences Ltd., 74 p.

EMERY, K.O., 1961. A simple method of measuring beach profiles. Limnology and Oceanography, 6, 90-93.

Gray, J.M., 1988. Coastal cliff retreat at the Naze, Essex since 1874: pattern, rates and processes. Proceedings of the Geologists' Association, 99, 335-338.

Gulyaev, S. and Buckeridge, J.S., 2001. Erosion Monitoring and Prediction on an Urban Seashore. Proceedings of International
Ecological Engineering Conference, (Lincoln University, Lincoln, New Zealand), pp. 161-167.

Jones, D.G. and Williams, A.T., 1991. Statistical analysis of factors influencing cliff erosion along a section of the West Wales Coast U.K. Earth Surface Processes and Landforms, 16, 95-113.

Jones, J.R.; Cameron, B., and Fisher, J.J., 1993. Analysis of cliff retreat and shoreline erosion. Journal of Coastal Research, 9, 8796

Kermode, L.O., 1992. Geology of the Auckland urban area. Scale 1: 50 000. Institute of Geological and Nuclear Sciences geological map 2. Lower Hutt, New Zealand. Institute of Geological \& Nuclear Sciences Ltd., 63 p.

Kidner, D.; Dorey, M., and Smith, D., 1999. What's the point? Interpolation and extrapolation with a regular grid DEM. Pro. ceedings of the 4th International Conference on GeoComputation '99 (Virginia, USA). Published on CD-ROM. Produced by: J.Diaz, R.Tynes, D.Caldwell, J.Ehlen. Publisher: "GeoComputation CDROM". Paper 82, 1-27.

LEICA, 2000. TPS300 Basic Series. User Manual TC(R) 303/305/ 307 (Version 2.1.1). Leica Geosystems AG, Heerbrugg, Switzerland, $128 \mathrm{pp}$.

PALM, M. and LoHR, U., 2001. Surveying coastal erosion by airborne aser scanning. Integrated Coastal Zone Management, 1, 141-144.

Rosengran, N.J., 1985. The changing outlines of Sertung, Krakatoa Island, Indonesia. Zeitschrift für Geomorphologie, Supplementband $57,105-119$.

SMITH, G.L. and ZARILLO, G.A., 1990. Calculating long-term shoreline recession rates using aerial photographic and beach profiling techniques. Journal of Coastal Research, 6, 111-120.

Turbotr, C., 2001. Surveying the coast by airborne laser. Coastal News, 16, 2-3.

WISE, S.M., 1998. Digital terrain models-trap for the unwary. Proceedings of the 3rd International Conference on GeoComputation '98 (University of Bristol, Bristol, UK), Paper 80, 1-18.

Wray, R.D.; Leatherman, S.P., and Nicholls, R.J., 1995. Historic and future land loss for upland and marsh islands. Journal of Coastal Research, 11, 1195-1203. 